\title{
Local economic development and territorial competitiveness in Latin America
}

\author{
Iván Silva Lira
}

Iván Silva Lira

Director, Local and Regional Development Management Area

Latin American and Caribbean Institute for Economic and Social Planning (ILPES) Economic Commission for Latin America and the Caribbean (ECLAC)

•• ivan.silva@cepal.org

his article argues that the local and regional governments of Latin America, in an increasingly globalized world, must face new challenges that include establishing or improving their competitive strengths and transforming their local production systems. These two aspects must be linked to territorial policies and, more specifically, to the development of a territorial culture that embraces both. While it is true that enterprises are the ones that actually compete, their competitiveness may be enhanced if the territorial environment encourages this dynamic and if they themselves realize the importance of being enterprises "of the territory" rather than "in the territory". This objective may be thwarted, however, by the existence of territories that are unequally prepared to meet these challenges. Different types of intervention need to be used, therefore, in terms of local and regional policies, to enhance the competitive strengths of such territories. 


\section{I}

\section{Introduction}

In formulating subnational public policies today, it should be assumed that the scientific and technological revolution has had, and continues to have, a very significant impact on territories. National economies, in particular, have become more interdependent; this process has been accompanied by a thorough restructuring of production processes, which have become more flexible as new technologies arise requiring the development of fresh know-how in order to apply them.

Globalization brings with it many important changes for the future of subnational territories. From the cultural standpoint, a two-pronged movement can be seen: on the one hand, there is a tendency towards homogenization of cultural identities; on the other hand, a certain resistance to that trend and a return to a localized approach may be observed. Meanwhile, in terms of the time variable, the style and pace of life continue to accelerate, and barriers and distances between places continue to fall, owing to transport and telecommunications developments, which help make the territories more accessible from the standpoint of traditional territorial attraction factors.

All these recent changes are fostering increasingly open and decentralized societies, redefining the place and meaning of territories in the global village (Boisier, 1996); territories must therefore face new challenges in designing their development strategies in a context of greater complexity, openness, competition, uncertainty and rapid change.

Thus, it has been suggested that in the new global economy the only territories that can compete are those that learn, that is, those capable of adapting to the world's changing production patterns, on the basis of knowledge (broadly understood) and its application to the advanced tertiary sector, high-tech industry and/or agribusiness. This means that subnational territories need to develop their skills and advantages, or their capacity to build them, in order to become specialists in areas or sectors that have possibilities for being incorporated into the global market. To the extent that globalization encourages the transformation of subnational territories into spaces in the international economy, territorial division and the social division of labour will be reinforced. This dynamic, moreover, may obey a different logic depending on the horizontal or vertical division of territories, based on their links with other areas of the world (vertical logic) or their capacity to build networks or organizations within the same territory (horizontal logic).

Vertical logic could be defined as that applying to transnational firms, which can segment their production processes and spatially distribute production; this encourages the prioritizing of territorially selective criteria through the development of a limited number of locations that have the necessary strategic factors to promote the expansion and competitiveness of their enterprises. Horizontal logic, on the other hand, is closely related to the social construction of territories and, more specifically, with the idea of building innovative and competitive territories, making the territorial meso-economy an essential unit of analysis in promoting key opportunities for encounters between actors - public, social and private - with a view to modifying the production apparatus and encouraging economic growth with equity.

In this last context, the development of competitive advantages has a clearly local character: the national economic structure can be expressed in terms of local production chains, which foster the development of small and medium-sized enterprises (regardless of their links with large enterprises and methods for attracting foreign investment). These tend to seek associative and coordinated ways to gain competitive advantages, by forming clusters of enterprises organized on the territory or other types of productive associations where the achievement of economies of scale is regarded as external in the case of firms, but internal with regard to territories. 


\section{II}

\section{Objectives of local economic development}

The deep-seated transformation of the economic system in most Latin American countries that began in the 1980s showed that the opening of domestic markets, deregulation and privatization were not enough either to ensure that firms would be internationally competitive or to produce high levels of economic growth with a clear improvement in income distribution and living conditions.

Especially at the territorial level, it is increasingly important to design public management tools and policies to stimulate the exploitation of endogenous local resources that will foster new development styles based on the potentialities of local economies, as an essential complement to national development policies.

In general, the main objectives of territorial development are to change local production systems, increase production, create jobs and improve living standards. In pursuit of these objectives, it is important to bear in mind the institutional design and public management styles that have been adopted by subnational governments in Latin America to promote productive development policies and thereby change local enterprise systems in a climate of greater competitiveness.

In this context, to varying degrees, and particularly since the $1990 \mathrm{~s}$, a number of Latin American countries have begun to incorporate a territorial approach in their policies for encouraging productive development and promoting small enterprises that is more consistent with the objectives of establishing or enhancing the competitiveness of local production systems. Productive development organized from a local/regional perspective ${ }^{1}$ has the advantage, first, of being more closely in line with business demand, owing to the greater proximity to "customers". Secondly, it may be directed towards local enterprise systems rather than individual firms, which yields the obvious benefits of agglomeration, stimulates learning by interaction and therefore promotes innovation in economic activities.

The achievement of these objectives, however, requires, among other things, a decentralized,

\footnotetext{
${ }^{1}$ In this article, unless otherwise indicated, the term "regional" means subnational regions.
}

subnational institutional setting and an active process of strategic planning of territorial productive development, setting priorities and channelling the existing development tools towards common goals. The full operation of a system of decentralized productive development makes it possible to take advantage of potential increases in productivity in the territories, which then has an impact on the national aggregate growth rate in an environment of greater competitiveness.

The recognition that, in order to develop competitive strengths, small enterprises need to join together and also count on government support to help to correct market failures primarily linked to weaknesses in the capital, finance and credit markets, the training of human resources and technological innovation, largely justifies the development policies that have been designed. Thus, as seen in one of the excellent evaluation studies made on small enterprises in Chile (Bianchi and Parrillo, 2002), there are basically three factors that contribute to the success of small and medium-sized enterprises (SMEs):

(i) Integration into a dynamic productive and social system to allow for economies of sufficient scale and scope to compete with large enterprises in the global market;

(ii) Improvement in the quality of output, production processes and human resources, since it is impossible to continue to compete in global markets by price (there are actors that are too powerful, because their use of economies of scale enables them to squeeze out any competing country);

(iii) Dissemination of know-how and competencies so as to build a local economy that can produce high added-value, good quality and innovative goods. Know-how gives the enterprise a competitive advantage that makes it more resistant to being squeezed out.

Thus, besides the more traditional reasons for supporting the advance of small enterprises, there are also considerations related to the idea of local enterprise systems, collaboration to promote competitiveness, associative enterprises, public-private linkages, generation of know-how through interaction and development of competitive advantages that go beyond 
the notion that enterprises are the only ones that compete.

In this context, we strongly suggest the concept of territory as the cultural basis for enterprise systems that can develop competitive strengths in collaboration with their environment, accomplishing much more than the single, isolated development strategy of small enterprises. The scheme presented in figure 1 summarizes this concept. It is proposed that local and regional development is an eminently endogenous process that seeks to take advantage of its own potentialities - natural, human, institutional and organizational - to change local production systems in order to improve living conditions.

Innovation is necessary in order to make local enterprise systems more competitive; this requires, from the standpoint of social organization, consensusbased development projects that represent all territorial actors sharing a common view of the strategic areas that must be promoted.

Local production systems are of course made up of enterprises. According to statistical evidence, microenterprises, small and medium-sized enterprises

FIGURE 1

\section{Conceptualization of local and regional development processes}

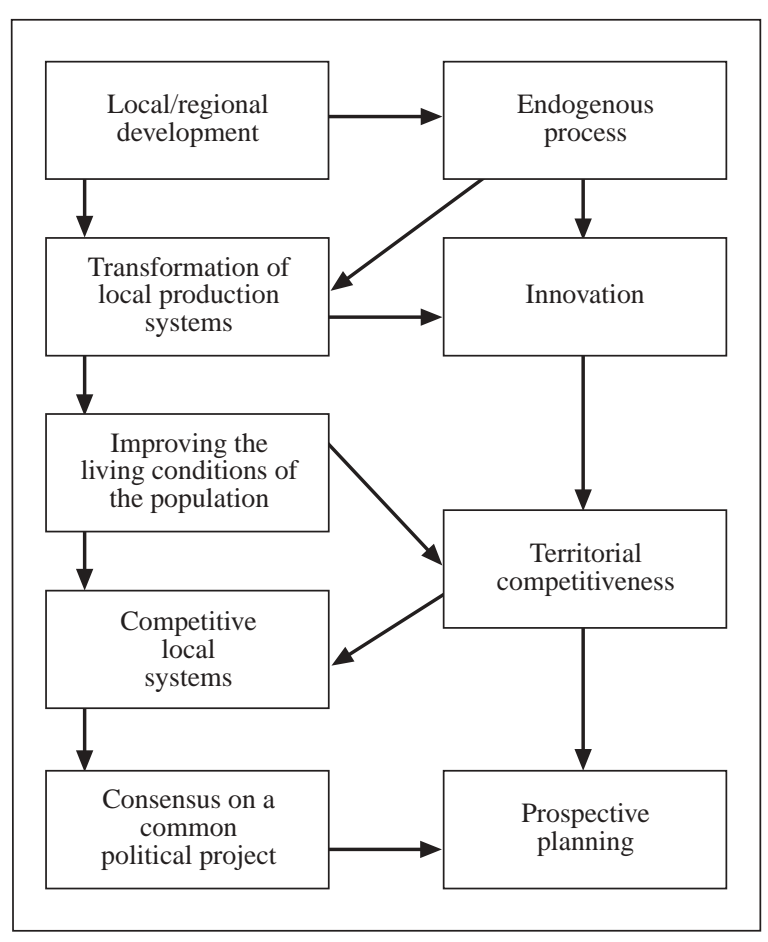

Source: Prepared by the author. are, in that order, the most homogeneously distributed over the territories. In Chile, for example, large enterprises constitute slightly less than $1 \%$ of formal enterprises in the country (4,814 in 1997), and nearly $73 \%$ of these are concentrated in the Metropolitan Region. Microenterprises and small enterprises, at the other extreme, constitute $97 \%$ of all enterprises and are distributed fairly homogeneously throughout the whole country, similarly to the relative population distribution (table 1).

Thus, when we speak of changing local production systems, in practical terms we are saying what must be done, for example, to improve the competitive strengths of some of the 3,757 enterprises in the Aysén region in Chile $(1,600 \mathrm{~km}$ south of Santiago), of which 3,256 are microenterprises and 486 are small and medium-sized (table 1). This region has a particular production and service profile, and some of its greatest advantages are associated with aquaculture and tourism, so that all policies proposed in this region to modernize the entrepreneurial system must necessarily take into account the local production network. It is unlikely that this can be tackled solely on the basis of a national perspective deriving from the centre of the country.

Moreover, from the standpoint of better strategy and more efficient allocation of resources, it is unlikely that all the enterprises in the region can be helped. Many of them will inevitably disappear, ${ }^{2}$ as a result of the dynamics of the markets themselves, although a

\footnotetext{
${ }^{2}$ See Cabrera, de la Cuadra and others (2002), which notes that the high failure rates among SMEs, the category of enterprises that is less successful than large enterprises, only confirms the pattern of behaviour of the emergence, development and disappearance of enterprises in a number of countries of all types. This trend is more a result of the habitual functioning of the economy than to any periods of recession it may pass through. Moreover, these processes favour aggregate economic growth, since most of the increase in productivity is due to the replacement of inefficient plants and enterprises by more efficient ones. Therefore, and this is the most striking conclusion, policies of support for ailing microenterprises and small and medium-sized enterprises will only postpone the disappearance of a great number of relatively less productive enterprises, waste government resources that could be put to more urgent use, and hinder the growth of productivity, employment, wages and the economy in general. In other words, according to this view, government policies to promote growth among microenterprises and SMEs will do nothing but block the progress of the economy, waste resources and delay the elimination of enterprises that are doomed to fail anyway; logically speaking, it would be better to let the market automatically resolve these allocation problems. Even if we disagree with this approach, the lesson that can be drawn from it is that development tools must be allocated to enterprises whose future technical and economic viability has been accurately assessed.
} 
TABLE 1

Chile: Number and percentage of enterprises, by size and region, 1997

\begin{tabular}{|c|c|c|c|c|c|c|}
\hline \multicolumn{2}{|c|}{ Region } & \multirow{2}{*}{$\begin{array}{r}\text { Micro } \\
14776 \\
87.5 \%\end{array}$} & \multirow{2}{*}{$\begin{array}{r}\text { Small } \\
1834 \\
10.9 \%\end{array}$} & \multirow{2}{*}{$\begin{array}{c}\text { Medium } \\
213 \\
1.3 \%\end{array}$} & \multirow{2}{*}{$\begin{array}{r}\text { Large } \\
67 \\
0.4 \%\end{array}$} & \multirow{2}{*}{$\begin{array}{c}\text { Total } \\
16890 \\
100.0 \%\end{array}$} \\
\hline I & Tarapacá & & & & & \\
\hline II & Antofagasta & $\begin{array}{r}12650 \\
82.6 \%\end{array}$ & $\begin{array}{c}2291 \\
15.0 \%\end{array}$ & $\begin{array}{r}273 \\
1.8 \%\end{array}$ & $\begin{array}{r}103 \\
0.7 \%\end{array}$ & $\begin{array}{r}15317 \\
100.0 \%\end{array}$ \\
\hline III & Atacama & $\begin{array}{c}7619 \\
85.6 \%\end{array}$ & $\begin{array}{c}1142 \\
12.8 \%\end{array}$ & $\begin{array}{r}108 \\
1.2 \%\end{array}$ & $\begin{array}{r}33 \\
0.4 \%\end{array}$ & $\begin{array}{r}8902 \\
100.0 \%\end{array}$ \\
\hline IV & Coquimbo & $\begin{array}{r}17647 \\
86.8 \%\end{array}$ & $\begin{array}{r}2373 \\
11.7 \%\end{array}$ & $\begin{array}{r}236 \\
1.2 \%\end{array}$ & $\begin{array}{r}70 \\
0.3 \%\end{array}$ & $\begin{array}{r}20326 \\
100.0 \%\end{array}$ \\
\hline V & Valparaíso & $\begin{array}{r}4528 \\
83.9 \%\end{array}$ & $\begin{array}{r}7343 \\
14.1 \%\end{array}$ & $\begin{array}{r}793 \\
1.5 \%\end{array}$ & $\begin{array}{r}245 \\
0.5 \%\end{array}$ & $\begin{array}{c}51909 \\
100.0 \%\end{array}$ \\
\hline VI & O'Higgins & $\begin{array}{r}23864 \\
85.6 \%\end{array}$ & $\begin{array}{c}3582 \\
12.8 \%\end{array}$ & $\begin{array}{r}346 \\
1.2 \%\end{array}$ & $\begin{array}{r}91 \\
0.3 \%\end{array}$ & $\begin{array}{c}27883 \\
100.0 \%\end{array}$ \\
\hline VII & Maule & $\begin{array}{l}35250 \\
88.7 \%\end{array}$ & $\begin{array}{c}3996 \\
10.1 \%\end{array}$ & $\begin{array}{r}376 \\
0.9 \%\end{array}$ & $\begin{array}{r}116 \\
0.3 \%\end{array}$ & $\begin{array}{c}39738 \\
100.0 \%\end{array}$ \\
\hline VIII & Bío-Bío & $\begin{array}{r}48672 \\
85.2 \%\end{array}$ & $\begin{array}{r}7394 \\
12.9 \%\end{array}$ & $\begin{array}{r}811 \\
1.4 \%\end{array}$ & $\begin{array}{r}254 \\
0.4 \%\end{array}$ & $\begin{array}{c}57131 \\
100.0 \%\end{array}$ \\
\hline IX & Araucanía & $\begin{array}{r}24723 \\
86.2 \%\end{array}$ & $\begin{array}{c}3545 \\
12.4 \%\end{array}$ & $\begin{array}{r}333 \\
1.2 \%\end{array}$ & $\begin{array}{r}90 \\
0.3 \%\end{array}$ & $\begin{array}{c}28691 \\
100.0 \%\end{array}$ \\
\hline $\mathrm{X}$ & Los Lagos & $\begin{array}{r}31447 \\
84.6 \%\end{array}$ & $\begin{array}{c}5095 \\
13.7 \%\end{array}$ & $\begin{array}{r}450 \\
1.2 \%\end{array}$ & $\begin{array}{r}197 \\
0.5 \%\end{array}$ & $\begin{array}{c}37189 \\
100.0 \%\end{array}$ \\
\hline $\mathrm{XI}$ & Aysén & $\begin{array}{c}3256 \\
86.7 \%\end{array}$ & $\begin{array}{r}439 \\
11.7 \%\end{array}$ & $\begin{array}{r}47 \\
1.3 \%\end{array}$ & $\begin{array}{r}15 \\
0.4 \%\end{array}$ & $\begin{array}{r}3757 \\
100.0 \%\end{array}$ \\
\hline XII & Magallanes & $\begin{array}{r}5014 \\
80.8 \%\end{array}$ & $\begin{array}{c}1032 \\
16.6 \%\end{array}$ & $\begin{array}{r}130 \\
2.1 \%\end{array}$ & $\begin{array}{r}28 \\
0.5 \%\end{array}$ & $\begin{array}{r}6204 \\
100.0 \%\end{array}$ \\
\hline \multicolumn{2}{|c|}{ Metropolitan area } & $\begin{array}{r}150001 \\
75.5 \%\end{array}$ & $\begin{array}{r}38464 \\
19.4 \%\end{array}$ & $\begin{array}{r}6734 \\
3.4 \%\end{array}$ & $\begin{array}{r}3500 \\
1.8 \%\end{array}$ & $\begin{array}{r}198699 \\
100.0 \%\end{array}$ \\
\hline No in & formation & 13984 & 275 & 20 & 5 & 14284 \\
\hline Total & & $\begin{array}{r}432442 \\
82.1 \%\end{array}$ & $\begin{array}{r}78807 \\
15.0 \%\end{array}$ & $\begin{array}{r}10870 \\
2.1 \%\end{array}$ & $\begin{array}{r}4814 \\
0.9 \%\end{array}$ & $\begin{array}{r}526933 \\
100.0 \%\end{array}$ \\
\hline
\end{tabular}

Source: Production Development Corporation (CORFO), on the basis of information from the Chilean Internal Revenue Service (SII).

strategic intervention should also be devised to support those enterprise systems that are most likely to succeed. Hence the need for a shared public-social-private view of what such intervention should look like.

A similar situation exists in the Atacama region (800 km north of Santiago), which has more enterprises than the Aysén region but represents a much higher proportion of microenterprises $(86.8 \%)$ and has a very different production profile; its productive development policies should therefore be designed on the basis of other considerations. The culture of different territories represents, among other things, different histories, varied skills and unique ways of doing things that are linked with specific natural environments and geographical features. All these aspects influence the existing forms of economic and social organization and must be taken into account when intervention strategies are designed. This is where the local approach to productive development policies in general, and promotion policies in particular, have the greatest validity. 
It is natural to suppose, then, that productive development policies should have a definite territorial stamp, at least with regard to local enterprise systems. Many governments have begun to see the situation this way, and they have gradually incorporated this view into their strategies, although to varying degrees of depth and with only relative but recognizable success.

\section{III}

\section{Local development in a globalized world: towards the building of competitive and innovative territories}

The building of competitive strengths may in fact be linked to territorial policies and, more precisely, to the development of a territorial culture that integrates local enterprise systems and helps to reverse the deteriorating situation of the most backward territories. In other words, although it is the enterprises that actually compete, their competitiveness may be reinforced if the territorial environment is conducive to this dynamic and if the enterprises, for their part, recognize the importance of being enterprises "of the territory", whose inhabitants are entitled to some benefit, rather than enterprises "in the territory", totally divorced from its future development plans.

It is important to understand, in particular, that in a local approach, public management may lead to the development of networks, or clusters, of enterprises having a base in a particular territory, where the collaborative and associative nature of the enterprises are key factors in promoting their competitiveness.

The word "clusters" refers to a geographical concentration of enterprises and institutions, in which interaction generates and sustains competitive advantages. No consensus yet exists on the Spanish equivalent of the term, with various phrases (agrupamientos industriales, distritos industriales and agrupaciones locales being used, often with different meanings. ECLAC practice is to use the term aglomeraciones productivas. The main idea is that, by developing such agglomerations, or clusters, it would be possible to create further competitive advantages (chiefly know-how and innovation) that are of particular importance for groups of SMEs concentrated in a single territory.

In other words, there is convincing evidence that organized collective action in general, and government action in particular, represent important sources of competitiveness. Porter (1991) has noted that the strength and durability of these clusters' ability to compete lie in their innovative capacity. These "superior" sources of competitiveness stem from interaction between enterprises that are able to both compete and cooperate with each other. In this particular model, government action is exogenous; that is, it may have an impact (beneficial or detrimental) on competitiveness, but cannot explain it. In this view, the role of government action is similar to that of causality. This approach is unsatisfactory, however, for those who design and carry out collective actions and public policy, particularly when today there is a need to promote public-private linkages to drive the development of these groups of enterprises (Buitelar, and 2001b).

It has become quite clear, therefore, that a basic element of competitiveness, especially in today's information and knowledge society, is the capacity for learning and innovation that seems to be latent in local institutions and organizations and that could and should be exploited. Thus the shaping of the concept of territorial competitiveness should be one of the basic lines of action taken by subnational governments.

Figure 2 combines the concepts of clusters and local development. It attempts to illustrate that a number of enterprises may coexist in a territory and may develop the capacity to join forces, compete, cooperate, form linkages, learn and specialize in order to exploit the whole chain of value of a given production process as much as possible. To gain strength, these clusters require, in the local and regional context, the activation of two types of competition, the meso-economic and microeconomic levels of systemic 


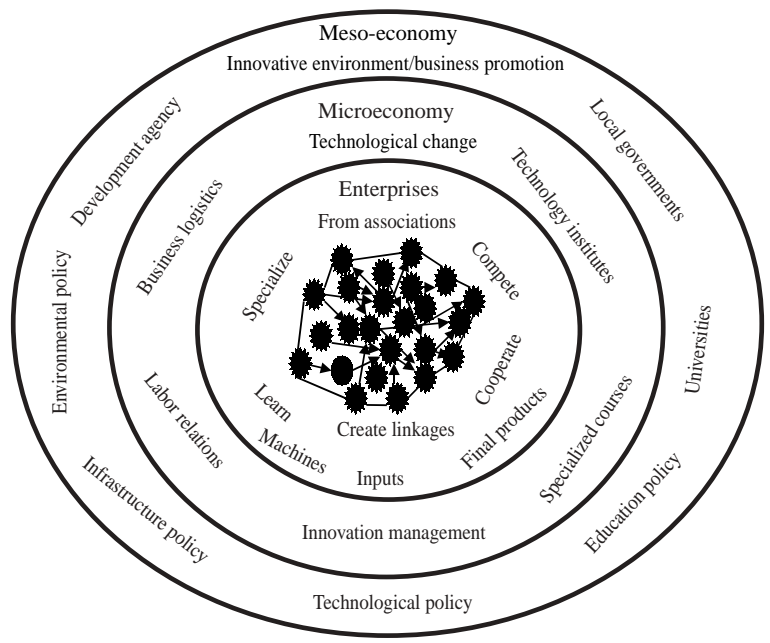

Source: Prepared by the author.

competition, which make the most sense and have the greatest economic impact at the territorial level. ${ }^{3}$ Figure 2 shows that, at the microeconomic level, technological changes are introduced that are feasible and necessary to boost the local system of production, for which various methods could be used. Meanwhile, at the territorial meso-economic level, an innovative environment is encouraged, which will help promote industry; this will require the development of a whole local institutional framework to tackle the challenge effectively.

In order for this step to be feasible, however, and for real progress to be made towards the implementation of successful local development initiatives, subnational governments must take on a new role, particularly with regard to the territorial meso-economy and microeconomy and public-private linkages, to help strengthen the competitiveness of the enterprises belonging to local systems, with all the demands and consequences this entails at the social, cultural, political and educational levels. These new subnational government functions, added to the traditional roles of government, are basically as follows:

- A role as creator of a favourable environment for local development;

- A leadership role, capable of activating and channelling social forces towards a common development plan;

- A role as public-private coordinator and promoter of business associations;

- A role in fostering production and the development of the meso-economic and microeconomic levels of systemic competitiveness.

Ultimately, for territories to become more competitive and innovative, they must take advantage of their endogenous resources, encouraging the formation of associations and public-social-private linkages with a view to making production processes more flexible. These dynamics are still rarely seen in the approaches taken by Latin American subnational governments. The meso-economic and microeconomic levels are more pertinent to the territorial context: if they are not strengthened, they are unlikely to succeed. The idea is gaining ground that it is actually territories that compete, even when they are unevenly prepared to undertake this task, as will be seen in the next section.

\footnotetext{
${ }^{3}$ In this context, the words "meso-economy" and "microeconomy" stem from the concept of systemic competitiveness, whose purpose is to find the economic and political determinants of successful industrial development and whose key ingredients, according to Altenburg, Hillebrand and Meyer-Stamer (1988) are "at the metalevel: first, development-oriented cultural values which are shared by a large part of the society; second, a basic consensus on the necessity of industrial development and a competitive integration into the world market; third, the ability of social actors to jointly formulate visions and strategies and to implement policies; at the macrolevel: a stable and predictable macroeconomic framework. This should include a realistic exchange-rate policy and a general foreign-trade policy that stimulates local industry; at the mesolevel: specific policies and institutions to shape industries and their environment (technology institutes, training centers, export
}

finance, etc.) and create a competitive advantage. Moreover, it is the [role] of local and regional industrial competitiveness initiatives to strengthen the firms' environment. Many of the institutions that act at the mesolevel are typically, or can in principle be, nongovernment entities, e.g. business associations or nonprofit entities; at the microlevel: capable and continuously improving firms, and networks of firms, with strong externalities". As a way of summarizing the idea of systemic competitiveness, one could say that the metalevel refers to the actors' capacity for community development and strategic consensus-building; the macrolevel is related to the ability to ensure the right conditions for reproducing the accumulation regime; the mesolevel responds by creating an innovative environment for industrial promotion, and the microlevel ensures technological change in the existing productive and entrepreneurial network. 


\section{IV}

\section{Territorial growth, convergence and disparities}

The first element to be taken into account in terms of the varying strengths of territories is the issue of territorial convergence, a traditional concern of students of regional topics involving territorial inequalities and their behaviour through time. This concern is closely related to the various neoclassical theories of economic growth that have postulated the existence of automatic mechanisms leading to convergence, as opposed to those theories that have stressed the need for definite intervention to correct any disparities, and is also associated with the investigation of factors that could boost growth in the poorest regions of a given country. ${ }^{4}$

One of the authors who most strongly revived this debate in the 1990s was Sala-i-Martin, who pointed out in one of his studies on convergence that in the mid1980s the new notions of endogenous growth ${ }^{5}$ had held that the assumption of decreasing returns to capital led the neoclassical model to predict convergence among nations. On the other hand, the underlying constant returns to capital in all endogenous growth models led to the prediction of non-convergence. An empirical study of the convergence hypothesis was presented, therefore, as a simple matter of saying which of the two paradigms represented a better description of reality (Sala-i-Martin, 2000). Later in the same study, the author argues that in the early 1990s, neoclassical economists started their own counterrevolution. Salai-Martin (1990), Barro and Sala-i-Martin (1991, 1992a and 1992b) and Mankiw, Romer and Weil (1992) refuted the notion that the neoclassical model predicted convergence, thereby denying that the evidence

\footnotetext{
${ }^{4}$ For a detailed analysis of this topic and its application to different countries and regions, see Mancha Navarro and Sotelsek Salem (2001).

5 The term "endogenous growth" as used here denotes the incorporation of technical progress as an endogenous process in the model associated with research and development (R\&D) costs, as opposed to the former postulates of Solow's neoclassical model, whose key feature was to consider technical progress as an exogenous factor, with a production function characterized by replaceable factors of production, constant yields to scale and decreasing yields from the variable factors of production.
}

presented until then could be used to dispute the neoclassical model.

Beyond the interesting theoretical debate and the continuing empirical evidence generated by it, this section presents two of the definitions of convergence used, whose purpose, in this case, is to enquire into the evolution of territories within some Latin American countries. One of the concepts is the so-called beta convergence, which holds that there is convergence if poor countries grow faster than rich ones. The other is the sigma-convergence, whereby there is convergence if the real per capita income dispersion between economic groups tends to decrease through time. ${ }^{6}$

The sigma-convergence is presented below, but only for those countries on which disaggregated economic information could be obtained for intermediate subnational territories, namely, Bolivia, Brazil, Chile, Columbia, Mexico and Peru. ${ }^{7}$

First, we will review what has happened in terms of territorial convergence, that is, whether the growth of intermediate territories has been convergent, neutral or divergent in the periods analysed. It is interesting to see whether the poorest intermediate territories are growing at higher rates than the richest, and thereby determine whether there is greater equity in their growth at the national level. This verification, as we have already noted, is done in terms of sigmaconvergence (S) and beta-convergence (B). In both situations the per capita gross domestic product is used; while the first method means that there is convergence to the extent that the dispersion of real per capita GDP is reduced over time, that is, that the disparities between intermediate territories tend to diminish, the second refers to the speed of convergence, that is, the time it would take for the poorest intermediate territories to catch up to the richest. In this latter case, therefore, there is a beta-convergence between the intermediate territories if there is an inverse relationship between the

\footnotetext{
${ }^{6}$ Sala-I-Martin (1990) was the first to use these definitions.

${ }^{7}$ The intermediate subnational territories correspond to departments in Bolivia, Colombia and Peru; states in Brazil and Mexico; and regions in Chile.
} 
Latin America (six countries): Sigma-convergence for various countries

(Standard deviation of the natural logarithms of per capita GDP)

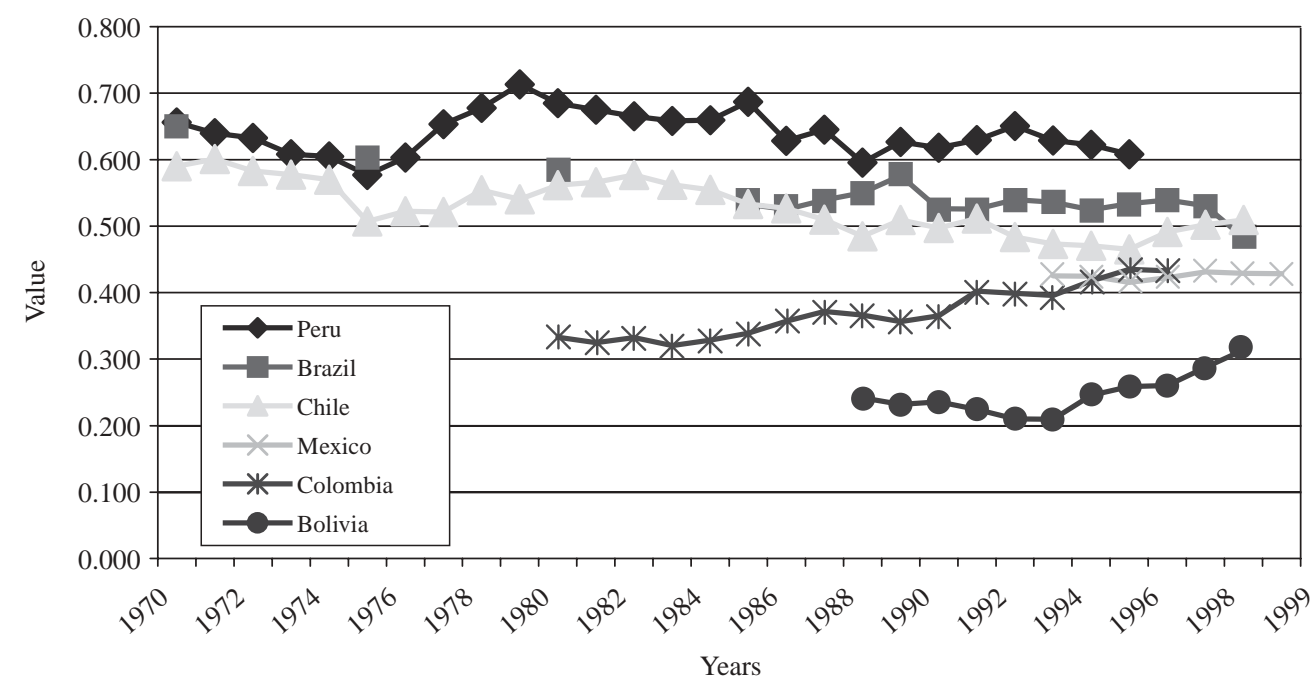

Source: Prepared by the author.

growth rate of per capita GDP and the initial level of GDP, in other words, if the relatively poorer territories tend to grow more rapidly than the richer ones.

Figure 3 presents the results of the sigmaconvergence for a number of countries. When the indicator approaches 1 , the disparities are very much accentuated, and when it approaches zero there is a greater degree of territorial equality. The time series are different: as can be seen, long series were obtained for Peru, Brazil and Chile, while for Mexico the series is very short, since it covers only the period from 1993 to 1999; in the case of Columbia it goes from 1980 to 1996, and for Bolivia, from 1988 to 1998. In other words, the difficulty of obtaining disaggregated information for intermediate territories is compounded by the fact that the series are not uniform for all countries and that they are not all as up-to-date as would be desirable.

As the figure shows, the greatest disparities between intermediate subnational territories are found in Peru, followed by Brazil, Chile, Mexico, Columbia and Bolivia, in that order. Besides showing the lowest degrees of inequality among these territories, Bolivia is the least developed, relatively speaking, of the territories studied, which could suggest that this situation reflects the low level of territorial development in all departments; in any case, this country started to show a growing increase in territorial disparities in 1994.
In Peru, from 1970 to 1995 , the indicator fluctuated between 0.60 and 0.70 , with a small decrease in disparities (greater convergence) between 1970 and 1976, after which they increased and then began to decline until 1989, when they again started to rise slowly. The periods of greater convergence in the Peruvian case seem to coincide with times of severe national economic crises, such as those of 1982-1983 and 1988-1989; in other words, this convergence is associated with poor economic performance during those periods.

In the case of Brazil, indicators fluctuated between 0.50 and 0.60 in the period 1970-1997, and also show fluctuations that do not reflect a clear trend towards an increase or decrease in disparities. A slight reduction in disparities is observed in Chile beginning in 1983, the year when, paradoxically, there was also a serious recession in the country; this trend reversed itself in 1996. For Mexico, the series is very short and indicates a virtually constant situation in terms of territorial inequalities from 1993 to 1999, while for Columbia there was a steady increase in territorial disparities from 1980 to 1996.

In brief, figure 3 shows that territorial disparities in the countries studied tend to remain steady or increase slightly through time, and that their decrease tends to coincide with periods of economic crisis; this suggests that the reason lies more in the sudden collapse of growth in the richer territories than in 
TABLE 2

Latin America (six countries): Analysis of subnational convergence and divergence (beta)

\begin{tabular}{|c|c|c|c|}
\hline Period & $\begin{array}{l}\text { Time required to } \\
\text { reduce gap by half }\end{array}$ & Period & $\begin{array}{l}\text { Time required to } \\
\text { reduce gap by half }\end{array}$ \\
\hline Perú & & Mexico & \\
\hline $\begin{array}{l}1970-1980 \\
1980-1990 \\
1990-1995 \\
1970-1995\end{array}$ & $\begin{array}{l}\text { No convergence } \\
51 \text { years } \\
\text { No convergence } \\
\text { No convergence }\end{array}$ & 1993-1999 & No convergence \\
\hline Brazil & & Colombia & \\
\hline $\begin{array}{l}1970-1980 \\
1980-1990 \\
1990-1997 \\
1970-1997\end{array}$ & $\begin{array}{l}35 \text { years } \\
48 \text { years } \\
\text { No convergence } \\
54 \text { years }\end{array}$ & $\begin{array}{l}1980-1996 \\
1990-1996\end{array}$ & $\begin{array}{l}\text { No convergence } \\
\text { No convergence }\end{array}$ \\
\hline Chile & & Bolivia & \\
\hline $\begin{array}{l}1970-1980 \\
1980-1990 \\
1990-1998 \\
1960-1998\end{array}$ & $\begin{array}{l}\text { No convergence } \\
53 \text { years } \\
\text { No convergence } \\
61 \text { years }\end{array}$ & $\begin{array}{l}1990-1998 \\
1988-1998\end{array}$ & $\begin{array}{l}\text { No convergence } \\
\text { No convergence }\end{array}$ \\
\hline
\end{tabular}

Source: Prepared by the author.

explicit policies to encourage growth in the more backward territories.

The data contained in figure 3 can be compared with those presented in table 2 , which shows the results of the beta-convergence, an indicator of the speed of convergence. ${ }^{8}$

In general, the speeds of convergence obtained are extraordinarily low. In the case of Chile, during the long period between 1960 and 1998, the results of the model show that it would take 61 years to halve the gap in per capita GDP between regions, whereas if the model is applied to the period 1990-1998, one of the highest growth periods in the history of the country -when it could be said that globalization forces were fully operative - there is no evidence of convergence between the subnational territories.

A similar situation is found in Mexico, where the model does not show any evidence of convergence between 1993 and 1999. Nor are there any indications of convergence for Bolivia during the periods studied, or for Peru in 1990-1995; the same is true of the situation of Columbia in the period 1980-1996 and also

\footnotetext{
8 See the attached table in the appendix, which presents further details on the results of the nonlinear regression for the various countries in the study.
}

in 1990-1996. In the case of Brazil, in periods where there are signs of convergence, the time it would take to reduce the gap by half steadily increases from 35 years in 1970-1980 to 54 years in 1970-1997. If the period 1990-1997 is taken in isolation, despite the fact that the correlation coefficient is not significant, there are no indications of convergence.

It may be concluded that there are no signs of territorial convergence in the countries studied, and it would therefore be useful to persist in seeking a more detailed diagnosis of the characteristics of the various subnational economies that might explain this behaviour to some extent,. To that end, we propose to build a typology of territories, distinguishing, for example, between rich and poor, or winners and losers, in order to enquire into what attributes make some of them winners, and what shortcomings cause others to be losers, with a view to identifying clear policies to enable the latter to converge towards stages of greater growth and development.

Figure 4 was prepared on the basis of available information. This figure ${ }^{9}$ shows the point of intersection

\footnotetext{
${ }^{9}$ A more detailed explanation of the construction of figure 4 is as follows: the horizontal line of the $x$ axis corresponds to the average growth rate of GDP at national level for the period under consideration. Thus, intermediate subnational territories located
} 


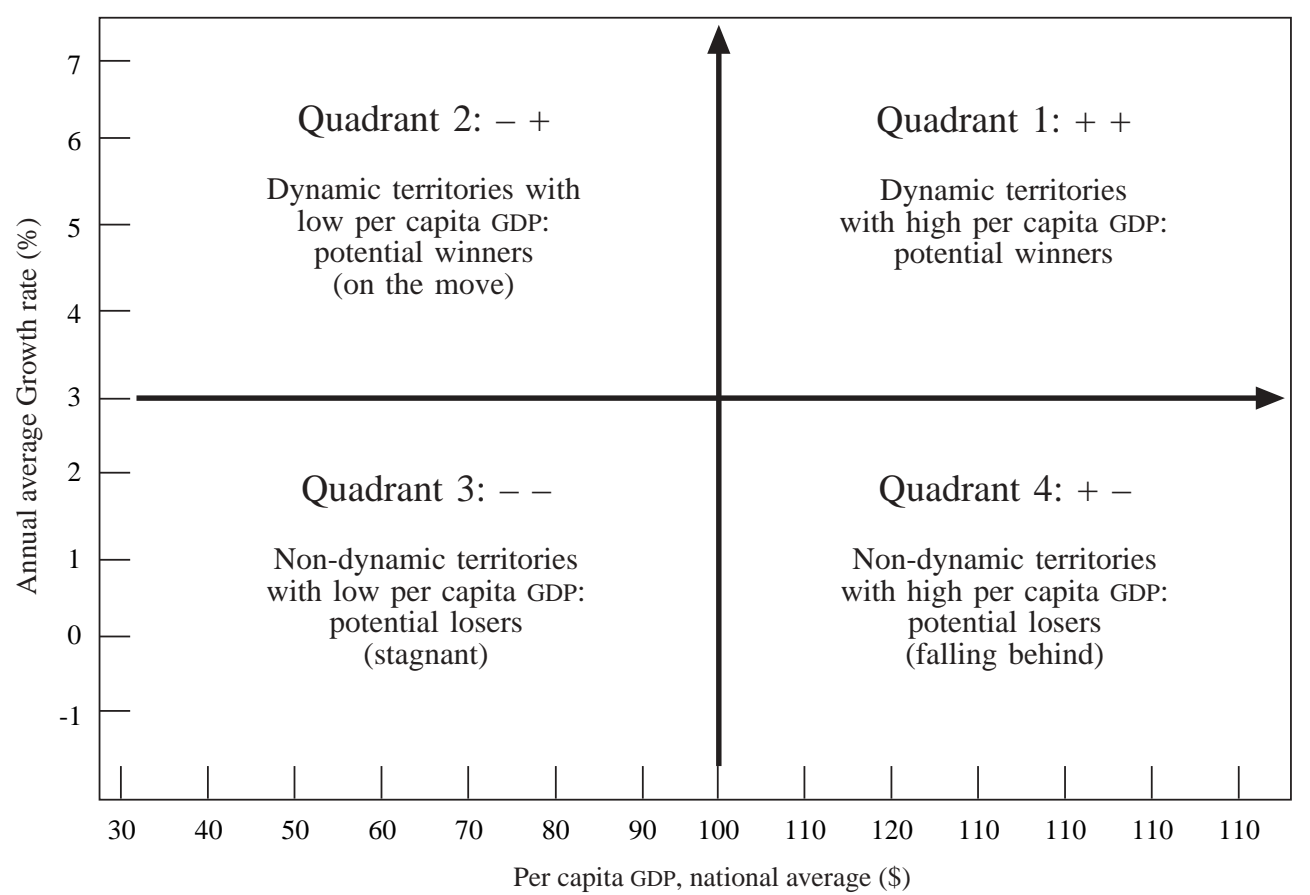

Source: Prepared by the author.

of two Cartesian axes which determine the configuration of four quadrants, which have different growth dynamics and allow for a possible interpretation of what is occurring in the various territories of the countries analysed. The specific territories corresponding to each quadrant are presented in table $3 .^{10}$

above this axis will be the ones that have grown more than the national average. The example in figure 4 shows that the national economy grew, in a given period, by an annual average of $3 \%$. Therefore, the territories located above this average growth will be considered dynamic and will be found in quadrants 1 and 2 . The vertical line, or $y$ axis, corresponds to average per capita GDP at national level, so that territories located to the right of this axis will have a higher per capita GDP than the national average. In the example in figure 4 , the average per capita GDP at national level is 100 monetary units, meaning that territories with average GDP above this level will be considered as having a high per capita GDP and would correspond to quadrants 1 and 4 . It can be seen that quadrant 3 represents the worst economic performance, since the territories in that quadrant have grown more slowly than the national average and also have a lower per capita GDP than the national average.

${ }^{10}$ For a more detailed analysis of this classification, see Silva Lira (2003).

\section{Quadrant 1: Dynamic territories with high per capita GDP, "potential winners"}

This quadrant contains territories that have grown faster than the national average and whose per capita GDP is also higher than the national average; they could therefore be considered as having the most successful behaviour in the context of globalization. ${ }^{11}$ They correspond to potentially winning geographic areas whose differences or gaps with the relatively less developed territories are accentuated or expanding.

This quadrant contains territories in situations that could be classified as follows:

(a) Potentially winning territories with exportable natural resources; these territories take advantage

\footnotetext{
${ }^{11}$ In reality, this classification first seeks to interpret what is occurring in intermediate subnational territories in different countries, and hence this framework of analysis will probably raise questions that will require other data to be processed in order to provide the right response. We speak of "potentially" winning territories, since, in view of the dynamic behaviour of economic events, being a winner today does not necessarily mean being one tomorrow; to continue to be a winner, very proactive policies are needed to deal with the globalization of the economy.
} 


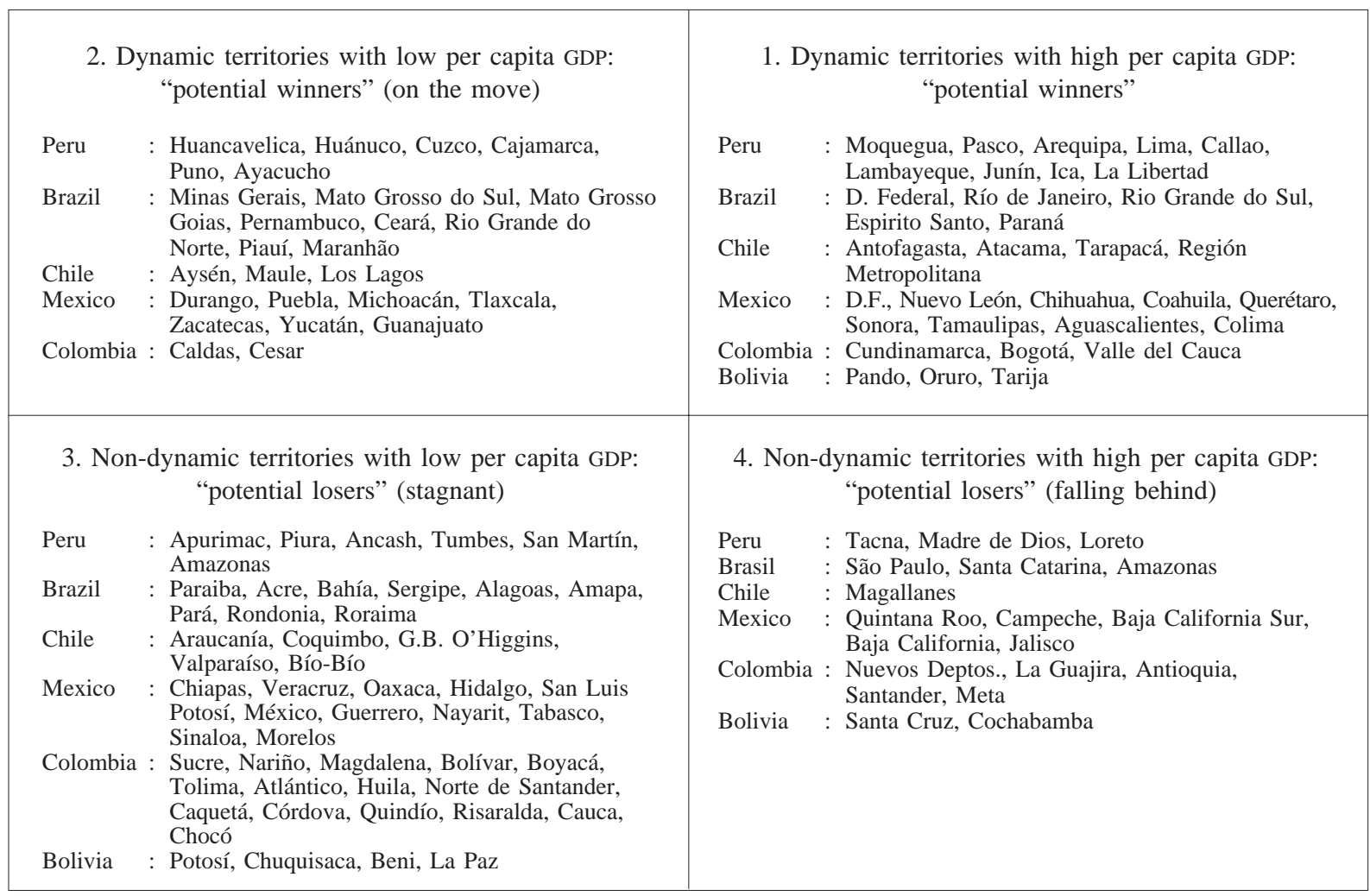

Source: Prepared by the author.

of very clear and marked comparative advantages, such as mining resources, which have allowed them to attract investment and gain an international position through their exports. Openness to private capital probably helped these types of territories, which largely compete on the basis of a natural advantage. It does not appear, however, that their productive and service networks have become sufficiently densified and diversified to effectively produce territorial clusters. In other words, although they are dynamic territories today, it remains to be seen whether they will be able to build advanced competitive advantages.

(b) Potentially winning territories that include metropolitan areas: this category contains metropolitan areas that have normally seen a considerable concentration of economic activity over time and have become important financial and service centres. These territories have either capital cities or large cities that have undergone a significant process of tertiarization of their economies, and whose urban environment is the source of the country's main connection with international financial markets.

\section{Quadrant 2: Dynamic territories with low per capita GDP, "potential winners", on the move}

This category includes territories that have grown faster than the national average but have a lower per capita GDP than the national average. They could be somewhat poorer or more backward than the others (as reflected in their lower per capita GDP), but they have good rate of growth and are thus approaching a situation that is closer to convergence with more dynamic territories, especially if their relatively greater vitality is maintained.

Generally speaking, these territories have initiated ppromising growth processes associated with new technologies and more recent restructuring of 
production, ${ }^{12}$ developing latent comparative advantages, mainly as an economic basis for commodity exports or for potentially adding value to their production processes on the basis of local resources. These could be characterized as potentially winning territories that have taken advantage of latent local resources, thanks to globalization.

\section{Quadrant 3: Non-dynamic territories with low per capita GDP, "potential losers", stagnant}

This quadrant is exactly the opposite of quadrant 1. It includes territories that have grown more slowly than the national average and whose per capita GDP is also lower than the country average. They are called "stagnant" and "potential losers", since if this trend continues their backwardness will increase, and they will fall still farther behind the more advanced countries.

In this quadrant, the following situations could be characterized:

(a) Potentially losing territories that have deindustrialized and have been unable to fully modernize their economies: these territories have industrial structures that were overly protected, and their economic performance has continued to fall behind; they have been unable to modernize their systems of production, and economic opening and globalization still represent a threat. Some local territories, however, coexist among them and might represent opportunities for change and innovation. (b) Potentially losing territories, with rural lowproductivity economies and scant human capital, which have been unable to gain a position in the global economy: these are traditional agricultural territories that have been normally backward, some of them with large indigenous populations; they require considerable attention from the central State in the form of compensatory policies to help stop their deterioration and identify specific recovery programs for each specific situation.

\section{Quadrant 4: Non-dynamic territories with high per capita GDP, "potential losers", falling behind}

This quadrant includes territories that have grown more slowly than the national average and yet have a higher per capita GDP than the national average. In the recent past these territories have done very well, having reached high per capita GDP levels, but they have undergone periods of recession that could threaten their recently improved situation; they are therefore considered to be falling behind.

This quadrant includes territories that have become less dynamic because their natural resources have been partially exhausted or because they have lost competitiveness and/or markets. It could be said that they have suffered a loss of comparative advantages, which could be permanent or temporary, depending on the local capacity for repositioning. These territories could be characterized as potential losers whose competitive strength has waned. ${ }^{13}$

\footnotetext{
${ }^{12}$ For example, new technologies that have allowed for the mining of deposits whose exploitation was not previously profitable.

${ }^{13}$ There is probably no exact correspondence between the established classification and the "cultural" knowledge one might have about some of the territories in the countries studied, in particular with regard to the use of expressions like "potential winners or losers". Some territories may feel that they have not been correctly classified. Although they may have this impression, we are simply trying to see whether it is possible to find some trends or behaviour patterns that would enable public policies to be identified and differentiated for each territory. What is clear is that if an intermediate subnational territory (region, department or state) has grown more slowly than the national average and also has a per capita GDP below the national average, it is a completely objective fact about
}

which little can be done, at least in terms of statistical manipulation. One example might be the case of Santa Cruz in Bolivia, which is generally known as one of the most dynamic and modern departments in the country. It is classified in quadrant 4 , however, as "potentially losing or falling behind", because although its per capita GDP is high, it has a lower annual growth rate than the national rate. What is happening is that, in absolute terms, the economy of Santa Cruz has shown great vitality, higher than that of the country in general, but this vitality has not manage to compensate for the large influx of migrants; therefore, its GDP growth in per capita terms is below the national average rate, to which it paradoxically contributes significantly. This is clearly an exception to the rule that more typically applies to the behaviour of territories that tend to be located in this quadrant. 


\section{V}

\section{Responses for local development}

By linking the information discussed in the previous sections, particularly the analysis of territorial disparities and typologies, to the creation of competitive and innovative territories, we can try to establish what type of policies should be promoted depending on the characteristics of each particular territory. Some additional background information that should be taken into account in order to accomplish this includes the following:

- Not all territories are equally prepared to deal with the processes of opening and globalization;

- There are significant territorial disparities that call for different types of intervention in terms of local public policies;

- The technical and leadership capacities of subnational governments (local and intermediate) are not all the same;

- The rationale of comprehensive development and, in particular, of support for productive development processes is not fully incorporated into the subnational government agenda;

- Subnational development must be accompanied by decentralization, and additional efforts must also be made to decentralize the tools for productive and entrepreneurial development;

- Meso-economic and microeconomic plans for systemic competitiveness, although they may make more sense in the territorial environment, must be accompanied and supported by national industrial incentive policies and encouragement of technological innovation. Otherwise, subnational efforts may turn out to be ineffective.

What is ultimately important is to determine what can be done at the national level, and within each territory, to help the backward regions grow more rapidly, while allowing the more advanced territories to maintain their good economic performance. As noted by Cuadrado Roura (2001), in the context of his studies on regional convergence in Europe, that macroeconomic growth models continue to suffer from a significant omission. The spatial factor, or territory, almost always remains on the sidelines, whereas many of the factors whose importance is crucial because they explain, or might explain, the higher economic growth rate are localized. In other words, these factors are not objectively transferable from one place to another; they are either not very mobile or they tend to remain in a given area. This explains why, although the shortage of capital in the most backward subnational regions should make these regions, according to conventional theory, more attractive to investment and external saving, what really happens is usually the opposite, because the productivity of a capital-deepening investment or an investment in physical capital may be low if it is not accompanied by investments in human and technological capital.

Accordingly, in another section of the abovementioned study, Cuadrado Roura (2001) adds that the latent advantages and better resources in a given territory not only make it more attractive to external investment and easier for it to mobilize its own potential, but they incorporate factors that may produce higher yields. Ultimately, these factors mean that the territory in question can be more competitive than others, and hence the enterprises that set up business there can also be more competitive. Moreover, this also makes it easier to make local production systems more competitive, as explained earlier.

Cuadrado Roura analysed the factors explaining the faster growth of 16 subnational territories in the European Union. The factors that seem to determine better economic success in the European Union, and which should be taken into account when trying to identify specific public policies to encourage the development of the most backward regions, include the following:

(i) A system of mid-level cities with medium-sized populations $(40,000$ to 150,000 inhabitants), which seems to constitute a clear advantage for the growth and localization of activities, together with the availability of skilled human resources and a moderately solid educational base. If relative labour costs are also moderate, the territory has an added advantage;

(ii) Physical accessibility of the territory; accessibility of the territory and its agents to international markets; possibility of access to political and administrative decision makers in the country; access to innovations and technological advances;

(iii) Availability of advanced production services, such as strategic planning, technological advisory assistance, design, marketing and exporting, 
research and development $(R \& D)$ and specialized financial services;

(iv) Advanced territorial institutional framework: for example, a territorial government with high levels of competencies and autonomy with respect to the central administration, a system of regular cooperation between authorities and with civil society organizations (chambers of commerce, business and social organizations);

(v) Favourable social climate, associated with low levels of labour conflict and good cooperation between the various public and private institutions;

(vi) Significant presence of small and medium-sized enterprises (SMEs), representing a local entrepreneurial base that is prepared to take new initiatives (Cuadrado Roura, 2001).

These factors, although they represent the European way of thinking, should make us think about the type of capacities we need to develop in order to succeed in an increasingly globalized world. At least this is how Boisier understood it, from the standpoint of a Latin American scholar, since he has stressed in innumerable articles the need for territories to develop greater technological and innovative complexity in order to stand up to the challenge of an increasingly complex world. In one of these articles, in particular, he said that the new strategic scenario ${ }^{14}$ derives from the intersection of two processes. On the one hand, a new geography is emerging, more virtual than physical, which is generating new ways and means of territorial organization, and new types of regions are arising, based on a systemic rationale rather than technocratic voluntarism. Once the organized territories have become new actors in the international competition for capital, technology and markets, there will be a need to maximize their opportunities for emerging as

\footnotetext{
${ }^{14}$ This refers to the new scenario that must be faced by the territories, in which two processes of openness may be observed, one external and the other internal, which in turn stem from more complex processes. Boisier argues that the external openness is driven by globalization (which is in turn accelerated and enabled by the scientific and technological revolution) while the internal openness results from the ongoing functional, territorial and political decentralization (a mega-trend set in motion by this revolution, civil society's demands for autonomy, State reform and privatization); he suggests that there is a decisive interaction mechanism between the two forms of openness: there is no way to be competitive today if decision-making structures are centralized. In other words, one of the factors of success referred to by Cuadrado Roura, the presence of autonomous and decentralized governments, is seen here again as an essential condition for territories to be successful.
}

"winners" in this fierce global battle. In their empirical or speculative analysis of the characteristics of winning regions, various authors have drawn attention to such aspects as systemic complexity, speed of organizational decision-making, innovative capacity, flexibility, urban networking, infrastructure (heavy and light), autonomy of each government, culture, etc. Many of these characteristics are inversely associated with size, and the "small", whether beautiful or not, increases in value. Boisier suggests the concept of a pivotal region, arising as the basic unit of a pyramidal structure in which associative regions then appear as a result of agreements between contiguous territories; ultimately, the most powerful and post-modern virtual regions emerge, which are not subject to the limitations of spatial contiguity. Under these arrangements, respect for popular democratic will is unlimited. On the other hand, the strategic scenario is based on new forms of territorial management that make room for the notion of region as quasi-State and also as quasi-enterprise, using the first concept as a reminder of the fact that the regional development question is a political issue expressed in the form of relationships of dominance and dependence (hence the need for any region to accumulate political power), and the second concept as an indication of the need to imbue regional governments with good management practice, in particular, the practice of strategic management (Boisier, 2000).

In brief, in the light of the above-mentioned studies, which basically address the issue of the "winning" or "losing" nature of certain territories, whether the proposal is made, in the one case, on the conceptual level and, in the other case, more on the empirical level, it is possible to list some of the conditions that would presumably make a territory a "winner". In general, these include heavy infrastructure (related to transport and communications) and light infrastructure (associated with production services), and the structural conditions of the territorial system in question.

From another standpoint, we may also speculate about what conditions should be present in the productive and institutional networks of the "winning" territories, and from that perspective focus on the "speed" of organizational decision-making, the "flexibility" of these structures that would give them a high level of adaptability to the environment, the systemic "complexity of territorial organizations" that would bring them into line with the complexity of the "globalizing game", the "resilience" or capacity to reconstitute a network damaged by exogenous factors, 
and, finally, the territorial "culture", which produces identity and particular features that can be transformed into a market niches.

Finally, given this picture - which is somewhat sophisticated - of all the conditions that territories should meet if they want to be winners, we see that although these conditions may be true and necessary, it may be difficult, in view of the significant existing territorial heterogeneity, for many territories to reach higher stages of development. Instead, we have the impression that most of the territories of Latin America would be far from capable of developing the aforementioned capacities, and thereby gain a successful position in the international economy.

Aware of this difficulty, we believe that, taking as a frame of reference the challenges we have presented here, it is crucial to be able to recognize the point of departure of each specific territory - for example, the typologies listed in the previous sectionand then to identify differentiated public policies for each of them. Thus, it is not a matter of using the conditions listed as a sort of verification list to find out whether each territory has been able to meet all the requirements, but rather of seeing how the various responses can be put into play at the social level, moving in the direction of territorial competitiveness, innovation, technological change, complexity, etc., that will be appropriate to the needs and possibilities of each particular territory.

On the basis of the above reasoning, this verification list should be only a reminder of some of the past or present characteristics of certain "winning territories", including perhaps the most important, the development of the ability to efficiently exploit endogenous local resources, while promoting the formation of associations and public-social-private linkages with a view to making production processes more flexible in the context of territorial-level strategic management processes aimed at changing local production patterns.

Figure 5 seeks to illustrate the possible meaning of the differentiation of policies depending on the typologies of territories and the factors bearing on the success of the so-called "winning territories".

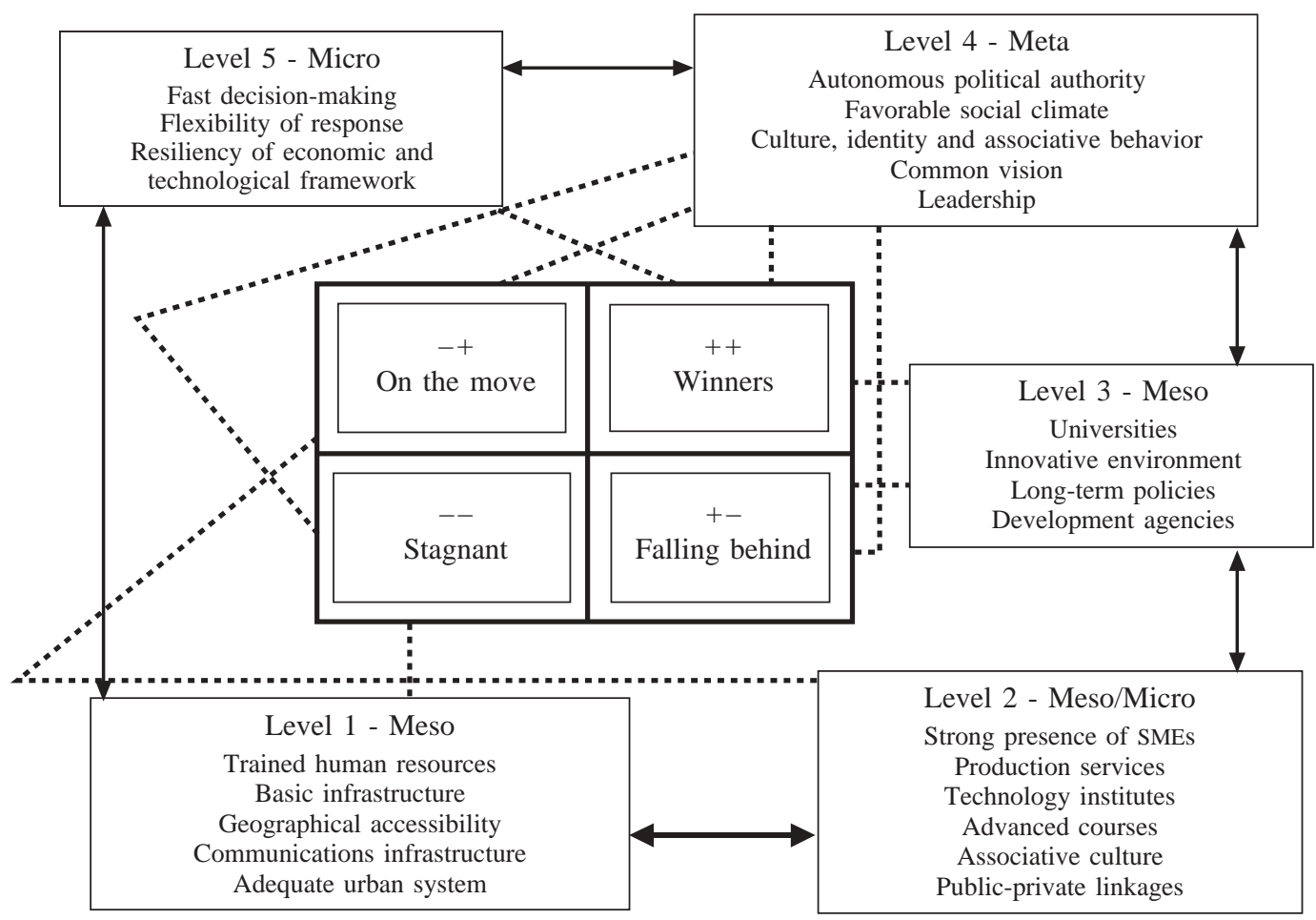

Source: Prepared by the author. 
Figure 5 groups together, at different levels, the presumed conditions of winning territories, and shows the relationship of these levels of conditions with the various types of territories. This figure may be interpreted as follows:

(i) Stagnant territories $(--)$ : in this case, the dotted lines identify the actions required at levels 1 and 4. Generally speaking, given the characteristics of these territories, more stress must be placed on the identification of policies aimed at the training of human resources - probably by increasing the number of years of schooling - and the development of basic infrastructure and other aspects mainly having to do with the lack of investment in tangible infrastructure, which may be blocking the advance of these territories (level 1 conditions). Level 4, which is common to all the territories, should be important for all of them, since it is mainly related to institutional and intangible conditions that usually do not require financial resources, such as autonomous political authority, favourable social climate, territorial culture and a common view of development.

(ii) Winning territories $(++)$ : At this other extreme, since these are winning territories that have presumably already met many of the conditions mentioned, there is more emphasis on promoting conditions classified in levels 3 and 5, that is, the existence of universities committed to the development of the territory, which provide the scientific and technological research associated with the regional production network; on encouraging and promoting innovative environments; and on building skills to promote faster decision-making and more flexible responses to a changing world. In other words, greater stress is placed on more highly sophisticated conditions, assuming that a critical mass exists to support them.

(iii) Territories on the move $(-+)$ : In this case, since these territories are making positive changes, but continue to experience backward social and economic conditions, there is more stress on promoting actions aimed at developing support services for production and encouraging technological institutes and advanced courses to train and retrain human resources, all of which characteristics are related to an active production apparatus that requires effective support in order to consolidate.

(iv) Territories falling behind (+-): Since these are territories whose economic and social evolution in the recent past has been positive, more emphasis is placed on aspects relating to the development of innovative capacity to resume the effort to recover lost growth and development. In these territories, where many of the efforts with regard to infrastructure, accessibility, urban system and other areas have probably already achieved some satisfactory results, the bigger challenges may be associated with certain transformations that might be necessary in order to gain a better position in the global economy.

Although the above-mentioned factors effectively help to reach "winning" positions, we should not discount the significance of development processes themselves and the different forms they can take. Thus, Celso Furtado's observation in the 1980s is even more relevant today:

I will make one final comment, derived from my contact in this and other countries with the problems of regions that have accumulated a long series of economic setbacks. For a long time there was a tendency everywhere to imagine that development was something quantifiable whose substratum was accumulation, investment, and the building of plant capacity. Experience has amply demonstrated, however, that true development is mainly a process of activating and channeling social forces, improving associative capacity and exercising initiative and inventiveness. Therefore, it is a social and cultural process, and only secondarily an economic one. Development occurs when there is a kind of energy in a society that is able to channel, in a convergent way, forces that were previously latent or dispersed. A real development policy must be an expression of the concerns and aspirations of social groups that are aware of their problems and try to solve them. Nevertheless, only political activity can channel these energies so as to produce the synergistic phenomena in question. What else but the growing weakness of political life can explain why, for us, development problems have become a matter of simple technical questions, with an overly simplified view of social and cultural processes (Furtado, 1982, translated from Portuguese).

Furtado's words are quite applicable to territorial development, since it is in the realm of relations established at the territorial level where it is most feasible "to channel, in a convergent way, forces that were previously latent or dispersed". This can be seen, to a large extent, as a matter of uniting behind a common vision, with the necessary leadership to inspire, at the local level, public and private agents who 
join together in a territorial culture that is their own, distinct culture and who are capable of undertaking innovative development projects based on the endogenous resource potential of the territory. In other words, without losing sight of the background chart which reminds us of the characteristics of the so-called "winning" territories, it is a matter of developing certain synergistic forms of capital, normally associated with intangible capital, to allow for a convergent channeling of dispersed forces and thus, with the same available resources, make faster and better progress towards the proposed objectives. ${ }^{15}$

This is a challenge that is still pending, for which many of the subnational territories of Latin America should be prepared because they have certain potentialities, such as very strong local identities; communities with fairly well-developed cultures of cooperation; decentralization processes going on at several stages of development; local governments that are increasingly aware of the need to guide and coordinate local development processes; a strong presence of SMEs with a relatively homogeneous territorial distribution; and industrial capacities that could be further promoted.

Finally, by elaborating responses to promote subnational development and build competitive and innovative territories, although based on very diverse realities because of the huge existing territorial inequalities, it is possible to see certain common and characteristic aspects:

(i) First, we have endogenous processes, in which we must develop the capacity to discover the potentialities —natural, human, institutional and organizational - of the territory, in order to know what we are "good at". In other words, we must have some area in which we are better endowed and trained and that could inspire our visions of the future;

(ii) The strategies to be formulated must be based on the concept of territorial solidarity through the affirmation of cultural identity. This ultimately means building, as a society, a territorial-level political project that gives the entire community a sense of ownership and manages to transform itself into a common vision of development that, having its own identity, will ultimately differentiate one territory from another;

(iii) The strategy should be based on the concept of partnership between public and private representatives; this entails the conviction that we cannot move forward alone and that we must therefore promote consensus-based projects that are also long-term and that transcend the sphere of any one particular government.

Without doubt, the challenge of promoting subnational development processes in Latin America will require enormous efforts, some of which are related to areas such as institution-building, organization, coordination and linkages, which do not always require financial resources, although of course some resources will be necessary. Thus, it is clear that there are opportunities for innovative political projects aimed at building competitive territories and hence transforming local production systems.

\footnotetext{
${ }^{15}$ Boisier (2000) describes in detail the intangible capital involved in development processes. In one section of this study he argues that, in any case, since development is an intangible result, its causality in this cultural dimension must be identified. In other words, what must be identified, in space and time, is what intangible factors lie behind development. Since these factors are very different, but can be grouped into relatively homogeneous categories, it is not inappropriate to introduce the concept of intangible capital to refer to groups of intangible factors. The author later lists the
}

types of intangible capital that might be present in a particular region: cognitive, symbolic, cultural, social, civic, institutional, psychosocial and human; in another section he adds that the finding of intangible capital more easily in small-scale territories only confirms the notion that development has always been and will continue to be a phenomenon that starts out on a small, local, decentralized and certainly endogenous scale. This statement is very important theoretically and practically, since in this view the community level and, at least in Chile, the provincial level take on a higher value. 
APPENDIX

Latin America (six countries): analysis of subnational convergence and divergence (beta)

\begin{tabular}{|c|c|c|c|c|c|c|}
\hline \multirow[t]{2}{*}{ Period } & \multicolumn{5}{|c|}{ Results of nonlinear regression } & \multirow[b]{2}{*}{$\begin{array}{c}\text { Time required to reduce } \\
\text { the gap by half }\end{array}$} \\
\hline & $\begin{array}{c}\text { Correlation coefficient } \\
\beta 1\end{array}$ & $\begin{array}{c}\text { Standard error } \\
(\beta 1)\end{array}$ & $\mathrm{T}$ & $\begin{array}{c}\text { Significance of } \\
\text { correlation coefficient }\end{array}$ & $\mathrm{R}^{2}$ & \\
\hline \multicolumn{7}{|l|}{ Peru } \\
\hline 1970-1980 & 0.011 & 0.013 & 0.858 & No & 0.038 & No convergence \\
\hline 1980-1990 & 0.014 & 0.006 & 2.382 & Al $5 \%$ & 0.237 & 51 years \\
\hline $1970-1995$ & 0.010 & 0.006 & 1.768 & No & 0.160 & No convergence \\
\hline \multicolumn{7}{|l|}{ Brazil } \\
\hline $1970-1980$ & 0.020 & 0.010 & 2.063 & Al $10 \%$ & 0.185 & 35 years \\
\hline 1980-1990 & 0.014 & 0.006 & 2.250 & Al 5\% & 0.196 & 48 years \\
\hline 1990-1997 & 0.011 & 0.012 & 0.866 & No & 0.033 & No convergence \\
\hline $1970-1997$ & 0.013 & 0.005 & 2.698 & Al $5 \%$ & 0.311 & 54 years \\
\hline \multicolumn{7}{|l|}{ Chile } \\
\hline 1970-1980 & 0.006 & 0.005 & 1.235 & No & 0.129 & No convergence \\
\hline 1980-1990 & 0.013 & 0.004 & 3.203 & Al 5\% & 0.516 & 53 years \\
\hline 1990-1998 & 0.004 & 0.013 & 0.320 & No & 0.010 & No convergence \\
\hline $1970-1998$ & 0.011 & 0.005 & 2.232 & Al $5 \%$ & 0.414 & 61 years \\
\hline \multicolumn{7}{|l|}{ Mexico } \\
\hline 1993-1999 & 0.002 & 0.006 & 0.318 & No & 0.00339 & No convergence \\
\hline \multicolumn{7}{|l|}{ Colombia } \\
\hline 1980-1996 & -0.006 & 0.008 & -0.814 & No & 0.025 & No convergence \\
\hline $1990-1996$ & -0.017 & 0.013 & -1.308 & No & 0.063 & No convergence \\
\hline \multicolumn{7}{|l|}{ Bolivia } \\
\hline
\end{tabular}

Source: Prepared by the author.

Altenburg, T., W. Hillebrand and J. Meyer-Stamer (1988): Building Systemic Competitiveness: Concept and Case Studies from Mexico, Brazil, Paraguay, Korea and Thailand, Berlin, German Development Institute.

Barro, R. and X. Sala-i-Martin (1991): Convergence across States and Regions, Brookings Papers on Economic Activity, No. 1, Washington, D.C., The Brookings Institution.

(1992a): Convergence, Journal of Political Economy, vol. 100, No. 2, Chicago, The University of Chicago Press. (1992b): Regional growth and migration: a Japan-United States comparison, Journal of the Japanese and International Economies, vol. 6, No. 4, Amsterdam, Elsevier Science, December.

Bianchi, P. and M. Parrillo (2002): Obstáculos y oportunidades de inversión para el desarrollo de las pequeñas y medianas empresas en Chile, Bologna, Italy, University of Ferrara.

Boisier, S. (1996): Modernidad y territorio, Cuadernos del ILPES series, No. 42, LC/IP/G.90-P, Santiago, Chile, Latin American and Caribbean Institute for Economic and
Social Planning (ILPES). United Nations publication, Sales No. S.96.III.F.1

(2000): Conversaciones sociales y desarrollo regional: potenciación del capital sinergético y creación de sinergia cognitiva en una región, Talca, University of Talca.

Buitelaar, R. (2001a): Como crear competitividad colectiva, La estrategia económica del Tolima, Tolima, Centro de Productividad del Tolima/Fondo Colombiano de Investigaciones Científicas y Proyectos Especiales (Colciencias).

(ed.) (2001b): Aglomeraciones mineras y desarrollo local en América Latina, Bogotá, D.C., ECLAC/Alfaomega.

Cabrera, A., S. de la Cuadra and others (2002): Las pyme: quiénes son, cómo son y qué hacer con ellas, Santiago, Chile, Sociedad de Fomento Fabril (SOFOFA).

Cuadrado Roura, J.R. (2001): Convergencia regional en la Unión Europea. De las hipotésis teóricas a las tendencias reales, in T. Mancha and D. Sotelsek (eds.), Convergencia económica e integración. La experiencia en Europa y en América Latina, Madrid, Ediciones Pirámide. 
Furtado, C. (1982): A nova dependencia, Río de Janeiro, Editora Paz e Terra.

Mancha Navarro, T. and D. Sotelsek Salem (eds.) (2001): Convergencia económica e integración. La experiencia en Europa y América Latina, Madrid, Ediciones Pirámide.

Mankiw, N.G., D. Romer and N. Weil (1992): A contribution to the empirics of economic growth, Quaterly Journal of Economics, vol. 107, No. 2, Cambridge, Massachusetts, The MIT Press.

Meyer-Stamer, J. (2000): Estrategias de desarrollo local y regional: clusters, política de localización y competitividad sistémica, El mercado de valores, vol. 60, No. 9, Mexico City, Nacional Financiera, September.
Porter, M. (1990): The Competitive Advantage of Nations, New York, The Free Press.

Sala-i-Martin, X. (1990): On Growth and States, thesis, Harvard, Harvard University.

(2000): Apuntes de crecimiento económico, Barcelona, Antoni Bosch editor.

Silva Lira, I. (2003): Disparidades, competitividad territorial y desarrollo local y regional en América Latina, Gestión pública series, No. 33, LC/L.1882-P, Santiago, Chile, Economic Commission for Latin America and the Caribbean (ECLAC), April. United Nations publication, Sales No. S.03.II.G.47. 